\title{
Politics of Language: The California Bilingual Education Initiative
}

\section{Amara Holstein}

This essay examines issues of power and multiculturalism in relation to the education of children through debate over monolingual versus bilingual education and how language is a source of power.

The initiative on bilingual education which passed in the 1998 summer election in California was touted by its detractors as the next anti-immigration initiative. The initiative called for an end to bilingual education, advocating instead to have one year of "sheltered immersion" in English for students who do not speak English. Under this initiative almost all children will be taught in English only unless requested otherwise by the parents of the child, and funds will be provided to parents who agree to tutor their children in the family's native language. Said by many to be another immigrant-hating piece of legislation, its supporters and opponents were expected to fall along similar lines to previous such legislation. As a lawyer for the Mexican American Legal Defense and Education Fund said, "This is the third in a chain of anti-immigrant, anti-Latino proposals" (Streisand 36).

The debates surrounding this initiative explicitly concerned 
bilingual education's efficacy and future worth. Educators and teachers came out strongly against this initiative for the most part, saying that it was a political move on the part of its main proponent and creator, Mr. Ron Unz. He has been characterized in all reports as a "wealthy businessman" who some said was using the issue of bilingual education to his own ends. Educators argued for the most part that bilingual education does work, and that it is, in fact, the best way for children to learn English and other subjects when English is not their first language. They see bilingual education as a means to keep the native language intact and to further the education of both English and the native language. To its opponents, then, the initiative was a racist attack against minorities and another attempt to further place these children in a disadvantaged position.

In these debates, however, the proponents of the initiative did not fall so clearly into the lines that the rhetoric assumed, and the issues surrounding this debate have not fallen into the expected pattern. People from different backgrounds who felt strongly about this issue had unexpected rections. Rather than most immigrants opposing the legislation, the situation was more complex than it initially appeared. With the exception of the proponents who explicitly wished to curb immigration and end multiculturalism, most of the proponents of this initiative were the immigrants themselves. These people did not deny that their children should keep their native language, and in fact many stated their desire that their children keep learning about their native culture and language. However, the arguments here suggested that the place of this cultural learning is in the home, not the school, and the school should be teaching their children English as the first priority.

This remains a debate more about power and who holds it and how language is a source of power. The school is a site around which these arguments take place, yet they go far beyond that of bilingual education. The parents see English as a form of power and wish to attain that power. The educators recognize this fact but want there to be other languages which are as powerful as English in the U.S. and see an end to bilingual education as an end to the fight for minority empowerment without assimilating into Anglo culture. 


\section{Background and Methods}

Because of the current debates centered around this issue and in light of the current climate after recent anti-immigrant initiatives it is necessary to further investigate the rhetoric behind this issue on both sides. The idea that immigrants voted for such a proposition seemed counter-intuitive since the program was ostensibly created for the benefit of immigrants. Thus to say that all supporters of the initiative were racists seemed too simplistic. Though this is only a brief survey of the ideas and arguments centered around the issue of bilingual education and by no means encompasses the views of all the people involved in this debate, the interviews and research give a tantalizing view into the way this debate was shaped by the rhetoric and individuals involved.

Since there are so many facts and figures already available for background information and since there was also a great deal of hypothesizing done by both sides on the nature of their opponents' arguments, the approach taken in this study is to interview in depth a sampling of people involved in this issue and then to use the vast wealth of other resources on this topic (both academic studies and media reports) as background and additional information. Ten formal interviews were conducted over the space of ten-weeks. The interviewees were chosen because of their diverse experiences in relation to bilingual education, and they were told the purpose of the interviews. The interviews were evenly distributed among teachers of bilingual education and people who spoke English as their second language but had various experiences with learning English as a second language (One woman was put directly into an English-only classroom; another was put into a Spanish-only classroom, and a third had children who had been in bilingual classrooms.) One interview was done with a young man who had been in a bilingual classroom and who was teaching English as a Second Language (ESL) in the Oakland school district in an after-school program. Four of the other interviews were with bilingual education teachers, two of whom identified themselves as being from other countries.

\section{Context}

It would be helpful to delineate exactly what is meant by 
the term "bilingual education" in the strictest sense of the word before going on to discuss how it is used as a political term in the current debates. Bilingual education is not a new concept in the last few decades, nor is it a unified concept meaning only one thing in terms of education. Bilingual education had its beginnings in the eighteenth and nineteenth centuries when students in various parts of the country were schooled in their native language upon coming to America as immigrants. German, Spanish, Czech, Italian, and Polish were among the languages which schools taught not only as foreign languages, but also as content-area instruction (Ovando 24). Indeed, in the 1910 census, Crawford points out that " 23 percent of foreign-born whites, 39 percent of Japanese, 41 percent of Chinese, and 66 percent of other immigrants spoke no English, as compared with less than 10 percent of foreign-born residents in 1990" (Crawford).

Yet the backlash against speaking languages other than English in the schools began right around the turn of the century. European nationalist sentiment began to rise, especially as new immigrants began arriving from southern, eastern, and central Europe, while the already-established immigrants from northern and western Europe "clamored for power to control institutions, and the one solution to the power struggle focused on schools" (Ovando 24) This in tandem with the idea of "Americanization" in light of the World Wars contributed to the decline of bilingual education in the schools. Languages other than English were seen as "bad." As opposition to the inclusion of other languages in schools and government increased, the tone was set not just against the other languages but also against the people who spoke them.

In California this opposition was made explicit on several fronts: debates over Spanish language rights and the translation of government documents into Spanish prompted one state legislator to say, "I have no regard for this demagoguery that panders to this foreign element, that follows it for years and years. . . . I speak whereof I know when I say that hundreds of those who pretend to be citizens of California are recent immigrants from Sonora and other portions of Mexico, some of them bandits, cutthroats, and robbers..." (Debates 2). And one California school official in the early 1900 s said that 
German was a language that "disseminates the ideals of autocracy, brutality and hatred" (Zimmerman 39 ). The only bilingual programs that took place at this time were those that were remedial and used only in special circumstances (Ovando 25).

Then in the 1950s and 1960s with the rise of new immigrants coming into the country English as a second language started to become a program widely instituted in schools, as students began to receive education at their level of English proficiency (25). Programs were started in bilingual education in Coral Way, Florida, San Antonio, Texas, and Rough Rock School on the Navajo reservation (Bay Area 4). Bilingual programs in Florida during the 1960s were instituted in response to the great wave of Cuban immigrants into Miami. Following these changes, in 1968 a statute was passed by Congress (Title VI of the Civil Rights Act of 1964), which gave money to bilingual education programs and was known as the Bilingual Education Act. With this and building on the civil rights movements of the time, bilingual education enjoyed a resurgence in popularity.

In 1974 the pivotal San Francisco court case, Lau vs. Nichols, went to the Supreme Court, and the decision set the precedent for future bilingual education programs. The case was a class-action suit in which a group of non-English-speaking Chinese immigrants brought suit against the San Francisco school system for failing to provide the 1,800 Chinese students with an equal opportunity to learn. The case did not deny the importance of learning English, but rather the decision was that equal opportunity and materials must be provided for these students and that the school must design a program to meet the language needs of the students. As the Supreme Court decision said, "We know that those who do not understand English are certain to find their classroom experience wholly incomprehensible and in no way meaningful" (Ovando 34). Based on this court decision and other decisions like it throughout the country, bilingual education programs were instituted and required in most states, including California.

Bilingual education as a program, though instituted in most states, is in no way uniform. The Bilingual Education Act defined bilingual education as "the use of two languages, one of which is English, as mediums of instruction" (Bay Area 4). 


\section{Ethnic Studies Review Volume 22}

Yet as many have pointed out, this definition is extremely broad and would include any school in which one class is taught in a language other than English. In fact, as Roberts points out, "Bilingual programs are so diverse that it is problematical to make generalizations" (370). The term "bilingual education" must be explained in terms of its most common forms in order to better understand the context and arguments in which it is placed. Two of the most common forms of bilingual education are the maintenance and the transitional programs, though ESL programs (related to which is the sheltered model proposed in the initiative), immersion, submersion, and two-way or enrichment programs are also all models that are commonly found.

The transitional model of bilingual education is one in which students with limited English skills are taught in both their native language and in English for a certain period of time until their English is deemed acceptable enough to succeed academically, at which point the student is withdrawn from bilingual classes and put in monolingual classes where English is the only language of instruction. This model is also known as providing the students with a "bridge" to move from their native language to English. The federal guidelines for this model suggest a time period of three years in which to move the child into an English-only classroom (Roberts 374). This type of model has been criticized for being too assimilationist (Roberts; Ovando and Collier) as well as for the short time period given to learn English. Ovando and Collier do suggest, however, that this type of model is useful to older students, who have already developed cognitive capabilities in their native language and for whom these skills can easily transfer to English (Ovando 39).

In the maintenance model of education, on the other hand, the emphasis is on continuing instruction and education in the native language while learning English and then continuing to learn and speak in both languages even after dual-language fluency is achieved. Ideally both languages would be "maintained" through the twelfth grade and even through college when possible. In these programs, in contrast to the transitional model of bilingual education, the student is expected to be bilingual and bicultural. Yet these programs do not always have 
the support of the language-minority parents (for reasons that will be detailed later). These programs must have large numbers of students with the same native language to exist, and there must be "interest and support in the community for having a bilingually educated population" (Roberts 375 ).

Another program that often is regarded highly is two-way enrichment bilingual education. In this program non-English speakers and English-only speakers are put together in a classroom, and both are taught two languages and work academically in both languages. An English-speaking student is often paired with a non-English speaking student, and they are supposed to use each other as resources (Ovando 41). These classes, therefore, include both minority and majority language speakers, and the goal here is pluralistic and aims at developing a bicultural and bilingual population.

Least assimilationist of all is the Canadian model of bilingual education, or the immersion model, in which the student is placed in a classroom in which a second language is the only language taught. This model, however, assumes that the students will be language majorities in their culture, not language minorities such as the immigrant children in the U.S. In Canada, therefore, this model has been used to teach English speakers French.

The model of immersion is often confused with the American model, which is termed "submersion" by educators (Roberts, Ovando and Collier). The goal in this model is to assimilate the child into U.S. society, and it puts non-native English speakers into English-only classrooms despite any lack of English skills the child may have. While this model is not legal for schools with non-native speakers of English, Roberts points out that often oversight or ignorance on the part of the schools leads to children being educated in this model. This is a much-criticized model by educators, who say that many such students in these programs "feel marginalized and drop out before finishing high school" (Roberts 372).

Another criticized model is that of English as a Second Language in which the language minority child is "pulled out" of academic classes to learn English. In ESL programs students are taken from their English-only classrooms at some point during the day (for a period of time ranging anywhere from 
twenty minutes to half a day) for concentrated instruction in English. Again, since the emphasis here is on the student learning English as fast as possible, this model is also said to be assimilationist by its detractors and inferior to the point of being only useful in addition to other models (Bay Area 11). Proponents consider it as good as other methods of bilingual education in a child's education (Alexander 9). And thus ESL is closely related to the sheltered immersion model proposed in the initiative. Sheltered immersion is basically an ESL program with some subject-area classes also taught in the native language of the children and is a time-limited program under the initiative. Once the students have learned English adequately, they are put back in the English-only classrooms full time.

\section{Analysis of Interviews}

Though the above models are important as a means with which to better understand the issues, rather than focusing on the efficacy of the models themselves (for which there are points and counterpoints on either side of each model and findings and studies to back all these points), the actual rhetoric and positioning which encompass these models of bilingual education provide insight into the focal point of the debate. Both sides seemed to agree that learning English is important for immigrant children and that school is the place where English should be learned. Yet what was at issue was the native language and what that language represents, as well as what English represents in relation to the native language. The debate here, though often couched in terms of the models above, often revolved more around issues of power and multiculturalism than the actual education of the children.

The arguments in this debate on both sides revolved around the issue of language and the idea of "speaking." No matter which position people took in terms of bilingual education, most people in this debate seemed secure in the idea that language is a powerful tool and that speaking is a means to assert that power. Having a "voice" is important. One interviewee, Maya, said, "Language is key." Another, Sonia, talked about the idea of languages as having "cultural capital" in Bourdieu's sense of the term: that languages provide access to modes of power and that by virtue of what one speaks, one's 
access and determination in terms of that power is established. Indeed, Sonia added, "Discourse is about modes of power." These languages are thus not seen as all being equal in American society, and this is where the real issues come into play.

Certain languages are seen as "marked" or "unmarked" languages; it is by virtue of where they stand in relation to their "markedness" that determines their access to power. Edelsky explains the difference between an unmarked language and a marked language in that the unmarked language is that which is "assumed" or taken for granted to be the language used in a certain domain and that the marked language will be any other language placed in relation to the unmarked (Edelsky 26). In the schools, then, English is seen as the unmarked language which everyone "should" learn, and the other languages spoken are marked, or "unnatural." For as Ovando and Collier define the terms, "expanding the concepts of marked and unmarked languages to the groups they most closely represent, unmarked culture in the United States tends to be associated with white, middle-class, Protestant, non-ethnic, English-speaking groups" (Ovando 118).

Marked languages are not objectified parts of society, however, nor do they stand alone; as Sonia pointed out, "Language is developed and used in interaction with others. It is a social tool; it doesn't stand on its own." Rather, marked languages are seen by many people as acting also as "markers" for those who speak the languages. "Language is linked to culture," Philip said. "There are certain values and understanding in a culture that give the language its meaning." Maria also maintained this importance of language to culture, saying that "Spanish language and their heritage are linked. Language plays a big part in culture, and the Mexican culture has a strong oral tradition which is very important." Perhaps this idea of language as "marking" people of a certain culture can best be illustrated with an example given by Edelsky that she encountered in her fieldwork as she watched two children interact:

Kathy: I can speak three languages - English and Spanish and Indian.

Katie: Well I can speak four - English and Spanish and Scotland and Jewish! 
Kathy: So! I'm gonna learn Flagstaff! (a city about 150 miles away) (21).

Even at the young age of six, then, language and culture are confused, and language becomes a marker for identity and other cultures ("Scotland" and "Jewish").

Often the "marking" of a person is obvious in terms of bilingual education, when children are placed in classrooms for Spanish-speakers based only on their last names, which "mark" them as part of a certain culture and, therefore, as part of a certain language. This happened to Maria's sister, who was put in a Spanish-bilingual classroom only by virtue of her last name, even though she spoke fluent English. The handbook put out by the Oakland School District also recognized this problem:

Spanish-surname persons in the Southwest are frequently called bilinguals although they may have no knowledge of Spanish at all. Misclassification on the basis of name is likely to continue until we recognize that the term "bilingual" is inappropriate unless the person concerned does indeed have some knowledge of two languages. The "nationality" of his surname is an unreliable indicator of which language or languages an American speaks (Bay Area 11).

In this way, "naming" becomes "marking" and makes all those who are "marked" by language into a marked culture, be it an accurate marking or not.

Thus even as language becomes the symbol for a culture, the dominance of one language over others becomes the excuse of one culture over all others. Mike, speaking about English, argued that education should "really emphasize English as the primary language. Yes, it's cultural hegemony, but some things just are that way. You know, you sometimes have to be a martyr for life. . . . it's basically saying, 'We're in charge here,' but that's the way it is." English is recognized as the language of dominance, the unmarked language, and at the same time is shown to be a cultural symbol. "We're in charge here" shows the self-conscious idea that English is the language of power and that those who speak English are the "we" who are the holders of that power over the others. 
Holly also saw English as that unmarked language of American society. As she was talking with someone about whether or not there is an "American culture," Holly argued that there is such a thing as an American culture and that it is "all the things that you think about when you think about the United States of America. You think about some of these banal kinds of things, like baseball and hot dogs and Hollywood, and you think about English as the language. ..." English becomes like apple pie: good and wholesome. So where does that leave those who are not part of this history of English and who are not part of this unmarked culture?

These people often are described by those in the interviews and those in the literature as being dominated by the unmarked language by virtue of their being marked. As Sonia said:

But if you speak with an accent or a different variety of English, you have a lot more fighting to do to prove yourself. This is not just about individuals but is a community issue. Whole communities are excluded from the mainstream because of their languages.

This domination of the marked cultures by virtue of their languages oftentimes results in the creation of a "silencing" of those marked languages and, therefore, a silencing of cultures. In this way the dominant unmarked culture dominates these marked cultures and maintains that hegemony that Mike addressed. And that silence becomes internalized by those who are marked, for as Soto writes after visiting a Latino senior citizens center, "A large sign at the top of a wall sums up the sentiment: 'Escuchar, Mirar, y Callar' ('Listen, Look, and Be Quiet' ). The strategy that this particular generation has internalized and passed on to the next generation is one of total passivity and subjugation" (Soto 21). As the Chinese American writer Frank Chin is quoted as having said:

The deprivation of language in a verbal society like this country's has contributed to the lack of a recognized Asian-American cultural integrity. . . . Language coheres the people into a community by organizing and codifying the symbols of the people's common experience. Stunt the tongue and you have lopped off the culture and sensibility (Cheung 7 ). 


\section{Ethnic Studies Review Volume 22}

Yet these "marked" categories are not only silences, but are portrayed in a poor light by unmarked culture. Again the legitimacy of English is emphasized, as those who do not speak English are seen as being "lesser" people. Holly spoke to this sentiment in her interview:

So I go to work in the morning, and I don't know what country I'm in; all the signs are in Spanish or Korean and the whole face of the city is absolutely different than it is in Pacific Palisades or Santa Monica or Venice Beach even - it's filthy; it's absolutely filthy, and you see your little street vendors, selling popsicles or whatever. . . you know, the people who are saying you can't take our culture away (Lambert 4).

Here Holly seemed to be equating the dirt with the fact that these people speak Spanish or Korean ("all the street signs" ), and she used these signs in a different language as the marker for her later point that it was bilingual education. Student's understanding in their native tongue makes school subjects accessible. The only debate is over which bilingual education model is most effective (Rodriquez 53). Indeed these sentiments were echoed by most of the teachers in the interviews with the exception of Holly.

At first glance, then, the proponents of bilingual education seemed to be holding fast to the idea of bilingual education because of its help in teaching children English and other subjects. Bilingualism is seen as a tool with which to help children learn the culture into which they have immigrated and a tool with which to teach children academically. As Paul stated, "Supposedly if you learn, master a language, then it's no problem for you to master a second language." And as Sonia said, "There is a great deal of evidence and studies that have been done to prove that bilingualism is a cognitive asset. It gives kids the ability to manipulate complex language codes and to transfer this to their academic work." The implication, then, is that bilingualism is good as a tool to help within school and good to help the children learn academically.

The argument around bilingual education and the initiative was thus placed in a dichotomous relationship of educator vs. policy maker, with the former "knowing" better than the latter, since after all the issue was being shaped in terms of language 
as an educational tool. As Sonia said, "Unz is a policy maker, not an educator." And when Philip was asked about his opinion concerning the debates surrounding bilingual education, he noted, "Well, first of all, it is all about politicians, not educators. These are people who have never taught. . .."

Yet it seems that behind this idea that bilingual education is only good in terms of being used as a tool to learn is the very important idea that bilingualism also is a tool of power for these students. Since language is a marker and English is the unmarked language in American society, it appears that the emphasis placed on bilingualism is explicitly also to help the children gain a medium of power that is not that of the unmarked category, that is, to empower the children through their native language rather than just having them assimilate into English-speaking culture. Therefore, an emphasis on both English and the native language will give children an advantage over their monolingual peers. Much of the debate by educators over of which bilingual program is most successful centers around which program is least assimilatory for the children. As Sonia stated:

People need to value bilingual education as a good. The first language needs to be an unmarked language; it needs to be unstigmatized. In any program, then, bilingual education would be valued over monolingual education. A lot of kids now want to speak English and they could care less about their native language. They can't speak to everyone. So kids should want to be bilingual. Kids should say, "You only speak one language; I speak two."

In this ideal languages that are marked now become unmarked, and all children are put into bilingual education programs. In fact many of the proponents of bilingual education discussed how their ideal was to have all students speaking all languages in bilingual classrooms. As Abbe said, "I think that every kid must learn more than one language," and Maria, talking about the model of the small school district where Anglo and Latino children are both learning Spanish and English added, "It is stupid to maintain ourselves as a monolingual culture."

Formal education is seen to be the place where this should 


\section{Ethnic Studies Review Volume 22}

happen, since in this way languages can become formally unmarked. In this way the children are portrayed as leading the United States into a new millennium of cultural cooperation; as Mancillas wrote,

This is a priceless resource: a new generation of Americans committed to preserving and strengthening a democratic and pluralistic U.S. society, but also having a birthright familiarity with Latin American, Asian or Middle Eastern societies. Think of what these children might contribute in an age of revolutions in communications and development that we, today, can hardly imagine (Mancillas 507).

The ideal here is one in which all languages are viewed in equal terms of power and that none are marked. Children thus become the banner-holders for a new generation of Americans, a position achieved through bilingual education and the power of cultures other than that of the Anglo-American Englishspeaker. As Abbe stated:

I think everybody under twenty-five understands that we need to learn more languages in this country, especially today with this incredible wide-open, NAFTA and all this stuff going on. . . . Our kids and their future careers, whatever they're in, are going to be enhanced by knowing more than one language.

Language has moved outside the classroom and is here envisioned as multiple discourses of power, moving into a global community in which American children are well-versed to deal with this new world. In this vision school becomes a training ground for a new tool in the power of multiple languages. George Solis wrote in the web page for SmartNation (a group that supports bilingual education),

Remember racism is alive and only one step short of being reinforced within our schools. Education is the key to anti-racism. . . .

He went on to ask about bilingual education,

Isn't this so that our students and children gain an opportunity to sit at the table of knowledge and equality with all children (Solis).

Soto asked,

Are American schools and communities willing to 
implement collaborative power models? Should the schools of a democratic nation insist that children's language and cultures be valued (Soto 95)?

\section{The "Other Side"}

The opponents of bilingual education do not share this vision of their children moving into a bilingual, multi-cultural world. Indeed their eyes are not even looking to this broader conception of power. Rather, most of these immigrants have their eyes firmly focused within the United States and are trying to figure out how to negotiate the boundaries of power and win within the current framework of that power. Whereas the proponents of bilingual education see native languages other than English as being the means within which to create a new power structure within American society through the school system, most immigrants seem more to be concerned with situating themselves within the existing system of power. These immigrants do not see the balance of power between the languages as being equal and so they react to this by wanting their children to learn only English in school. Maria talked about how materials were of lesser quality in the Spanish classrooms, and Edelsky discussed how even in a two-way bilingual program, English was still seen as the predominant language (Edelsky 19). Thus, the reality is still seen by most immigrants to be that power lies in the acquisition of English.

Indeed, the idea of power resting in the knowing of English is one which was explicitly used in the debates regarding the initiative as the main argument of most people against bilingual education. Feeling that bilingual education does not stress English learning to a great enough degree, these opponents believed that cultural and native language learning should take place in the home and that the school should educate the children in the medium of power. Unz argued, "The only way you can get a good job and succeed is if you speak English. .. , and schools are not doing a good enough job" (Riccardi). Philip addded that many parents are working in low-paying jobs because of their inability to speak English. One father said, "My children learn Spanish in school so they can grow up to be busboys and waiters. I teach them English at home so they can grow up to be doctors and lawyers" (O'Beirne 21). Ramon, the 


\section{Ethnic Studies Review Volume 22}

father of a teenager who is having problems in school, wanted his daughter to learn English and was not as concerned with Spanish; and Maya insisted that "English is needed to open doors-in order to have access to things, you need English. If I had a kid, I would only want that kid to learn English."

Speaking English is equated with social and economic success, based both on the parents' own experiences and on the idea of "The American Dream." As Lenin Lopez stated in Spanish at a parent meeting regarding bilingual education, " $A$ lot of us want our kids to learn Spanish so they can write to their grandpas or whatever. . . But I want my children to learn English so they won't have the problems that l've had," (Pyle). Spanish (and other non-English native languages) becomes the language of the private sphere, and English is regarded as the public language and the language of power.

These images are not to say that parents do not want their children to learn their native language. Rather, the parents seem to feel that it is the role of the school to educate their children in English above all else and that the native language can be taught in the home. Each language is seen as needing to be taught in the sphere in which that language will be used: the native language in the home, English outside the home (in school). Ramon, Maya, and Maria all agree with this idea. As Maya said most explicitly, "The role of the school is solely to expose the kid to the [English] language. If the child understands the language completely, then the school has done its job." This ideology would suggest that bilingual education is not actively teaching English to students fast enough, and that in not doing so the children are being held back from avenues of power to which only English can provide the entrance.

\section{Conclusion}

While the proponents of bilingual education did not seem to acknowledge the desire of parents for their children to be fully fluent in the current discourse of power, many immigrants seemed to look past a possible future in which multiple languages function as modes of power. Both sides of this debate focused on the issue of language as power and language as attached to culture and modes of cultural power. Yet the way in which these notions were explained takes on different mean- 
ings for each side. Rather than being split along racial lines, the sides of this debate seemed split more along the lines of the educators and the parents and politicians. The former saw the importance of learning academic subjects and the means with which to think cognitively as of foremost importance. Language is a means to the end of being "educated," and bilingual education is necessary to achieve this end. The educators and community activists also viewed bilingualism as the key to creating a multicultural society in which all languages have equal access to power and where all children can be powerful by virtue of rather than in spite of being bilingual. At the same time these people saw the dissolution of bilingual education programs as being an attack on the cultures of these immigrant students.

The parents, on the other hand, also focused on the issue of language as power. But unlike the educators who seemed to be saying that native languages are part of that power, the parents were saying that English is the language of power of the public sphere, and for their children to be part of that power, they must speak English. In this view, then, the school should be educating the children in that language of power, and teaching the children in the native language of the family should take place in the private sphere: in the home, in the community, through the church. These parents did not seem to want to be the founders of a new society in which bilingualism is powerful; rather, these parents wished for their children to enjoy the benefits that they cannot have because they have fewer skills. The parents saw power as resting in an institution they must be part of or which they will never benefit from.

The educators and supporters of bilingual education in this debate felt that it has been long enough that English has been the only language of power, and it has been long enough that people of color have been marked as inferior by their language and their culture. Unfortunately, in this fast growing multicultural, multiethnic society these two groups are still speaking past each other and have yet to create a meaningful dialogue in which modes of power can be explored with both parents and educators. 
Alexander, Susan H. and Keith Baker. "The Bilingual Education Movement: The Emergence of an Elite in an Exploited Minority Group," Migration World Magazine, 22 (March-June 1994), 9.

Bay Area Bilingual Education League. Handbook for Teachers, Parents, and Administrators. (Oakland: Oakland Unified School District, 1969), 3, 4, 11.

Cheung, King-Kok. Articulate Silences. (Ithaca: Cornell University Press, 1993), 7

Crawford, James. "Issues in U.S. Language Policy: The Official English Language Question." Webpage (http://www.smartnation.ore/wwwdocs/stories.htm), 5 May 1998.

"Debates of the Constitutional Convention of the State of California, 1878-1879." 2 (Sacramento: 1880-81), 801-802.

Edelsky, Carole. With Literacy and Justice for All: Rethinking the Social in Language and Education, 2nd ed. (London: Taylor \& Francis, 1996), 21, 26, 19.

Lambert, Wallace E.. "Bilingualism: Its Nature and Signiificance." Bilingual Education Series: 10: Facets and Faces of Bilingualism.

Mancillas, Jorge R. "Bilingualism: Assimilation is More Than ABC's." American Voices: Culture and Community, 3d ed. (Mountain View: Mayfield Publishing Company, 1997), 507.

Ouando, Carlos J. and Virginia P. Collier, Bilingual Education and ESL Classrooms: Teaching in Multicultural Contexts. (New York: MacGraw Hill, 1985)

O' Beirne, Kate, "Bread \& Circuses," National Review, 48 (1 July 1996): 21. 
Pyle, Amy. "Bilingual Schooling is Failing, Parents Say." Los Angeles Times (16 January 1996).

Riccardi, Nicholas. "Latino Crowd Hostile to Author of Bid to Curb Bilingual Teaching." Los Angeles Times. (9 November 1997).

Roberts, Cheryl A. "Bilingual Education Program Models: A Framework for Understanding." Bilingual Research Journal, 19 (Fall/Summer 1995): 370-75.

Rodriguez, Roberto. "The Politics of Language." Hispanic. (April, 1996): 53-56.

Solis, George Jorge. "Your Stories." Webpage: (http://www.smartnation.org/www/docs/stories/stories.htm), 1 May 1998.

Soto, Lourdes Diaz. Language, Culture, and Power: Bilingual Families and the Struggle for Quality Education. (Albany: State University of New York Press, 1997), 21, 46.

Strisand, Betsy. "Is It Hasta La Vista for Bilingual Ed"? U. S. News and World Report ( 24 November 1997): 36.

Zimmerman, Jonathan. "A Babel of Tongues: Debates Over Bilingual Education Are Almost as Old as the Republic." $U$. $S$. News and World Report (24 November 1997): 39 